\title{
ASSESSMENT OF PSYCHOLOGICAL RESPONSES AND RELATED FACTORS OF DISCHARGED PATIENTS WHO HAVE BEEN HOSPITALIZED WITH COVID-19
}

\author{
Neslihan Cansel ${ }^{1}$, Burcu Kayhan Tetik², Gülsüm Hilal Demir ${ }^{2}$, Osman Kurt ${ }^{3}$, \\ Bahri Evren $^{4}$ \& Aytac Yücel ${ }^{5}$ \\ ${ }^{I}$ Department of Psychiatry, Inonu University Medical Faculty, Malatya, Turkey \\ ${ }^{2}$ Department of Family Medicine, Inonu University Medical Faculty, Malatya, Turkey \\ ${ }^{3}$ Department of Public Healath, Firat University Medical Faculty, Elazlg, Turkey \\ ${ }^{4}$ Department of Endocrinology, Inonu University Medical Faculty, Malatya, Turkey \\ ${ }^{5}$ Department of Anesthesia and Reanimation, Inonu University Medical Faculty, Malatya, Turkey
}

received: 10.5.2021;

revised: 25.8.2021;

accepted: 1.9 .2021

\section{SUMMARY}

Background: COVID-19 is the biggest pandemic of the last century. While a large number of cases and mortality rates direct the research to the clinic and prognosis of the disease, the mental health of these patients has recently become a matter of concern. This study aims to predict psychiatric morbidity and possible associated markers in COVID-19 survivors.

Subjects and methods: A total of 102 survivors with COVID-19 infection participated in this study. A questionnaire was applied to the participants to evaluate demographic variables, history of comorbid diseases, smoking, loss of a relative due to COVID-19, and environmental attitudes after the discharge. Length of hospitalization, lung findings, intensive care history and treatments were recorded. Psychiatric morbidities were evaluated with General Anxiety Disorder-7, Patient Health Questionnaire-9 and The National Stressful Events Survey PTSD Short Scale.

Results: Anxiety was found in $20.6 \%$, depression in $13.7 \%$ based on moderate and above levels, $21.6 \%$ had significant PTSD. Female gender, history of psychiatric and comorbid diseases, smoking, perceived discrimination, and lack of long-lasting immunity posed a risk in terms of psychological response. There was a negative correlation between age and depression scores. No relation was found between the duration of hospitalization, presence of lung involvement, receiving intensive care treatment, losing a relative due to COVID-19 and psychological response.

Conclusions: On patients treated for COVID-19 infection, psychological response continue after discharge. Mental health support and efforts to reduce stigma among infected subjects can reduce the psychological impact caused by the pandemic.

Key words: COVID-19 - survivors - anxiety - depression - post-traumatic stress

$$
* * * * *
$$

\section{INTRODUCTION}

In February 2019, a new type of coronavirus of unknown origin was detected in patients affected by pneumonia in Wuhan, China. The virus was named as severe acute respiratory syndrome coronavirus-2 (SARS-CoV-2), and the associated disease was named 2019 coronavirus disease (COVID-19) (Gorbalenya et al. 2020). COVID-19 soon spread worldwide, and World Health Organization (WHO) declared the outbreak as a pandemic on March 11, 2020 (WHO 2020a). This study investigates the psychological response of people who were hospitalized with COVID-19 and later discharged.

Having a contagious disease can affect mental health. Symptoms of the disease, being isolated, complex drug treatments and side effects, being taken to intensive care or witnessing the death of a hospital roommate can cause traumatic effects (Xiao et al 2020, Xiang et al 2020, Huang et al. 2020). Fear of transmitting the disease to relatives or losing them, the anxiety of being excluded by society may cause mental impairment. (James et al. 2019). On the other hand, the virus itself may directly affect the central nervous system, leading to the development of psychiatric disorders (Holmes et al. 2020, Sinanović et al. 2020).

Data from previous pandemic periods showed that these effects continue for many years, even if the disease is over and will have serious psychosocial consequences. For example Wing et al. showed that approximately 50 percent of the people who survived Severe Acute Respiratory Syndrome (SARS) needed psychiatric treatment even 3 years after the epidemic was brought under control (Wing et al. 2012). In the study conducted by Mak et al. on the 30th month after SARS, this rate was reported as 33.3\% (Mak et al. 2009). Similarly, Park et al. found that $42.9 \%$ of those who survived Middle East Respiratory Syndrome (MERS) had post-traumatic stress disorder (PTSD) and $27.0 \%$ had depression at 12 months post-MERS (Park et al. 2020a). In a recent study, Liu et al. recorded that approximately half of the COVID-19 victims had depression and generalized anxiety disorder (GAD) (Liu et al. 2020). Considering that the number of people infected with COVID-19 worldwide exceeds 100 million (WHO, 2020b), it can be predicted that these rates will be much higher in the future. 
Studies investigating the psychological response levels of COVID-19 victims are still limited (Liu et al. 2020, Zhu et al. 2020, Park et al. 2020b, Bo et al. 2020). In this study, it was aimed to investigate the prevalence of generalized anxiety disorder, depression, PTSD, and the factors that may be associated with them in patients who were hospitalized and then discharged due to COVID-19. Identifying these factors can guide the authorities about the measures to be taken to protect the mental health of the patients.

\section{SUBJECTS AND METHODS}

\section{Study design and sample selection}

The study was designed as a cross-sectional study. The approval for the study was obtained from the Health Sciences Non-invasive Ethics Committee, Malatya Inonu University (2020/1265).

This study was conducted on a total of 102 participants who were hospitalized for laboratory-confirmed COVID-19 infection and later discharged from Turgut Ozal Medical Center in Malatya, located in the eastern province of Turkey between March $1^{\text {st }}$ and September $1^{\text {st }}$, 2020. The participants were treated in special inpatient services and intensive care units, which were separated from other patients, coordinated by the departments of infectious diseases, internal medicine, pulmonary medicine, and anesthesiology and reanimation. Clinical data and telephone numbers of the participants were obtained from the hospital's automation system. Data were collected between 15 and 30 November 2020 . The number of patients treated between these dates was 836. Eighty-seven of the patients receiving treatment had died. Twenty-six patients were excluded because they were under 18 years old. Among the remaining patients, 250 people were selected by randomization. Sixty-eight people could not be reached. Out of 182 people reached, 102 of them agreed to participate in the study. Participants were informed by the researcher about the purpose and content of the study, and verbal consent was obtained. The questions regarding the data form and scales prepared for the study were asked to the participants on the phone, and their answers were recorded.

\section{Data form}

Participants answered the questions about their age, gender, educational status, body mass index (BMI), income level, employment status, with whom they lived, smoking status, chronic internal disease history (hypertension, diabetes, cardiovascular disease etc.), psychiatric disorder history, any infected relative and if they lost any of their relatives due to COVID-19. The participants were also asked whether their complaints continued after discharge.

In addition, participants' discrimination experiences were also investigated. In the present study, inspired by similar study used by researchers to evaluate previous COVID-19 patients (Liu et al. 2020), a short 4-item scale of perceived discrimination was created. It included questions such as: "Have you been excluded by your family members because of your illness?", "Have you been excluded by the community or people at work?", "Have you ever felt that the people around you were afraid of you?" "Have you been subjected to insulting or ridiculing?" Each item was scored as "never" (score 0), "a little" (score 1), "moderate" (score 2), "severe" (score 3), and "very serious" (score 4). High scores indicated the height of perceived discrimination. The medical records of the participants were examined and the dates of hospitalization, duration of hospitalization, whether they received treatment in the intensive care unit, the treatment protocols applied and the findings in the chest tomography were recorded.

\section{Evaluation of psychological response}

To determine the psychological response of the participants, Generalized Anxiety Disorder Test-7 (GAD-7), Patient Health Questionnaire-9 (PHQ-9) and The National Stressful Events Survey PTSD Short Scale (NSESSS-PTSD) were used.

\section{General Anxiety Disorder-7 (GAD-7)}

GAD-7 is a 7-item self-report test developed by Spitzer et al. in compliance with the DSM-IV-TR criteria to evaluate generalized anxiety disorder (Spitzer et al. 2006). Each item is scored between 0 (not at all) and 3 (almost every day). According to the total scores that can be obtained from the scale, 5 indicates mild, $\geq 10$ moderate, and $\geq 15$ indicates severe anxiety. The Turkish validity and reliability of the scale was carried out by Konkan et al. (2013).

\section{Patient Health Questionnaire-9 (PHQ-9)}

PHQ-9 is a measure based on the Patient Health Questionnaire and questions 9 depression symptoms in compliance with the DSM-IV criteria (Kroenke et al. 2001). Each question is scored between 0 (not at all) and 3 (almost every day). According to the scoring system of the original questionnaire, scores between 1-4 were graded as minimal, 5-9 mild, 10-14 moderate, 1519 moderate severe and 20-27 severe depression. The questionnaire was validated and reliably adapted to Turkish in 2016 by Sari et al. (2016).

\section{The National Stressful Events Survey PTSD Short Scale (NSESSS-PTSD)}

The National Stressful Events Survey PTSD Short Scale (NSESSS-PTSD) was developed and approved for inclusion in DSM-5 (LeBeau et al. 2014). NSESSSPTSD consists of nine items, each assessing PTSD symptoms from four symptom clusters. The person is asked to rate the severity of symptoms that develop after a traumatic event on a 5-point scale (0 "not at all" - 4 "all the time"). The total score can range from 0 to 36 . 
The validity and reliability of the scale was made by Evren et al. (Evren et al. 2016). Similar to previous studies in this study (Liu et al. 2020), if at least one reexperiencing symptom, one avoidance symptom, two negative alterations in cognition or mood symptoms, and two arousal symptoms were present with a score of 2 (moderate) or higher, it was accepted as a significant level of PTSD.

\section{Statistical analysis}

The analyses were evaluated in the SPSS 22 package program (Statistical Package for Social Sciences; SPSS Inc. Chicago, IL). Descriptive data in the study were shown as $\mathrm{n}, \%$ values in categorical data, and mean \pm standard deviation (mean \pm SD) values in continuous data. Chi-square analysis (Pearson Chi-square) was used to compare categorical variables between groups. The compliance of continuous variables to normal distribution was evaluated by Kolmogorov-Smirnov test. In comparison of paired groups, the Mann Whitney $U$ test was used, and in comparison of more than two groups, the Kruskal Wallis test was used. Spearman correlation test was used in examining the relation of continuous variables with each other. Logistic regression analysis was used to calculate the risk of moderate and higher anxiety, depression and significant PTSD. The statistical significance level in the analyses was accepted as $\mathrm{p}<0.05$.

\section{RESULTS}

\section{The relationship between demographic features, data of the disease and psychological response levels}

A total of 102 participants, 45 (44.1\%) female and $57(55.9 \%)$ male, were included in the study. The average age of the participants was found as $44.4 \pm 13.7$, and the mean BMI was found as $27.1 \pm 3.8$. The highest level of schools completed by participants were primary school or below (42.1\%), high school $(27.5 \%)$, and university $(30.4 \%)$. Moreover, $51 \%$ of them were employed and $86.3 \%$ were living with their spouse and child. While $35.3 \%$ of the participants had a chronic internal disease, $7.8 \%$ had a psychiatric disorder, and $15.7 \%$ of them were smoking. In the analysis performed to determine the psychiatric response levels of the participants, it was found that $20.6 \%$ of participants had moderate or above anxiety, $13.7 \%$ had moderate and above depression, and $21.6 \%$ had significant PTSD.

The median duration of hospitalization of the participants was 4 days (IQR $=1-6)$. Patients hospitalized in intensive care comprised $4.9 \%$ of the total, and the average length of stay in this unit was $7.4 \pm 5.1$ days. Also it was observed that the complaints continued in $71.6 \%$ of the patients after discharge. The PHQ-9 score of those whose complaints continued after discharge was obtained as significantly higher than the score of those without complaints $(\mathrm{p}=0.013)$.
The lack of long-lasting immunity created anxiety in $68.6 \%$ of the patients. While any of the family members of $56.9 \%$ of the patients had been infected with COVID19, 2.9\% died due to COVID-19.

Radiological findings were observed in $77.9 \%$ of the patients who had chest CT. Cortisone was added to the treatment of $1.9 \%$ of the patients $(n=2)$, while the others $(98.1 \%)$ received only antiviral treatment. This data was not included in the analysis, as the rates of cortisone treatment intake were low.

The GAD-7 ( $\mathrm{p}=0.028)$, PHQ-9 $(\mathrm{p}=0.029)$ and PTSD $(p=0.002)$ scores of the women were found to be considerably higher than the scores of the men. The PHQ-9 score of those under 50 years of age was found significantly higher than those of the age group 50 and above $(p=0.04)$. The PTSD scale scores of those with chronic internal diseases were determined to be significantly higher than those without a chronic disease $(p=0.01)$. GAD-7 $(p<0.001)$, PHQ-9 $(p<0.001)$ and PTSD $(p<0.001)$ scores of those with psychiatric disorder were obtained significantly higher than those without psychiatric disorder. The GAD-7 ( $p=0.007)$, PHQ-9 $(p<0.001)$ and PTSD $(p=0.032)$ scores of smokers were found to be significantly higher than the scores of non-smokers.

Scores of those who answered "yes" GAD-7 ( $p=0.003)$, PHQ-9 $(p=0.003)$ and PTSD $(p=0.009)$ to the question: "Does the lack of long-lasting immunity cause you anxiety?" were observed significantly higher than of those who answered "no". Demographic features of the participants, the data of the disease and the scores of scales are given in Table 1.

\section{Evaluation of scale scores according to hospitalization date}

The hospitalization dates of the participants due to COVID-19 were respectively August (54.9\%), July (19.6\%), June (12.7\%), April (5.9\%), May (4.9\%) and September $(2 \%)$. There was a significant difference between the hospitalization dates of the patients in terms of GAD-7 ( $\mathrm{p}=0.036)$, PHQ-9 $(\mathrm{p}=0.049)$ and PTSD $(p=0.013)$ scores. The lowest of the scale scores was seen in those receiving treatment in June, while the highest was seen in those receiving treatment in September. The results of the comparison of the hospitalization dates and scale scores of the patients are shown in Table 2.

\section{Data on the perceived discrimination level experienced by the participants due to COVID-19}

While $84.3 \%$ of the participants were never excluded by family members due to their illness, $4.9 \%$ were a little excluded, $4.9 \%$ moderately, $3.9 \%$ severely and $2 \%$ very seriously. The percentage of the patients who were never excluded by people in the community or workplace because of their illness was 41.2 whereas $4.9 \%$ were a little excluded, $31.4 \%$ of them moderately, $6.9 \%$ severely, and $15.7 \%$ were very seriously excluded. 
Table 1. Comparison of demographic features, data of the disease and the scores of scales

\begin{tabular}{|c|c|c|c|c|c|c|c|}
\hline & & GAD- & & PHQ- & & PTSD sc & re \\
\hline & $\mathrm{n}(\%)$ & mean $( \pm \mathrm{SD})$ & $\mathrm{p}$ & mean $( \pm \mathrm{SD})$ & $\mathrm{p}$ & mean $( \pm \mathrm{SD})$ & $\mathrm{p}$ \\
\hline Gender & & & 0.028 & & 0.029 & & 0.002 \\
\hline Female & $45(44.1)$ & $6.3 \pm 6.2$ & & $5.8 \pm 5.3$ & & $9.7 \pm 10.3$ & \\
\hline Male & $57(55.9)$ & $3.8 \pm 4.9$ & & $3.6 \pm 5.0$ & & $4.1 \pm 7.5$ & \\
\hline Age & & & 0.795 & & 0.04 & & 0.475 \\
\hline$<50$ & $63(61.8)$ & $5.0 \pm 5.5$ & & $5.4 \pm 5.5$ & & $6.0 \pm 8.5$ & \\
\hline$\geq 50$ & $39(38.2)$ & $4.7 \pm 5.8$ & & $3.2 \pm 4.6$ & & $7.4 \pm 10.4$ & \\
\hline Education status & & & 0.975 & & 0.163 & & 0.770 \\
\hline Primary & $43(42.1)$ & $4.8 \pm 5.8$ & & $4.0 \pm 5.5$ & & $6.0 \pm 9.7$ & \\
\hline High school & $28(27.5)$ & $5.1 \pm 5.3$ & & $3.8 \pm 3.4$ & & $6.2 \pm 8.8$ & \\
\hline University & $31(30.4)$ & $4.9 \pm 5.7$ & & $6.1 \pm 6.0$ & & $7.5 \pm 9.1$ & \\
\hline Profession & & & 0.258 & & 0.241 & & 0.393 \\
\hline Employee & $52(51.0)$ & $4.3 \pm 5.0$ & & $4.8 \pm 5.3$ & & $5.9 \pm 8.3$ & \\
\hline Unemployed & $37(36.3)$ & $6.1 \pm 6.3$ & & $5.1 \pm 5.6$ & & $8.1 \pm 10.5$ & \\
\hline Retired & $13(12.7)$ & $4.0 \pm 5.3$ & & $2.3 \pm 3.5$ & & $4.7 \pm 8.7$ & \\
\hline Who do you live with? & & & 0.918 & & 0.151 & & 0.564 \\
\hline Living alone & $4(3.9)$ & $5.8 \pm 4.6$ & & $9.5 \pm 5.1$ & & $8.8 \pm 8.0$ & \\
\hline Parent & $10(9.8)$ & $4.4 \pm 6.2$ & & $4.9 \pm 4.1$ & & $3.8 \pm 7.3$ & \\
\hline Spouse-child & $88(86.3)$ & $4.9 \pm 5.6$ & & $4.3 \pm 5.3$ & & $6.8 \pm 9.5$ & \\
\hline Chronic disease history & & & 0.177 & & 0.661 & & 0.01 \\
\hline Yes & $36(35.3)$ & $5.9 \pm 6.1$ & & $4.9 \pm 6.6$ & & $9.7 \pm 11.8$ & \\
\hline No & $66(64.7)$ & $4.3 \pm 5.2$ & & $4.4 \pm 4.4$ & & $4.8 \pm 7.0$ & \\
\hline Psychiatric illness history & & & $<0.001$ & & $<0.001$ & & $<0.001$ \\
\hline Yes & $8(7.8)$ & $13.3 \pm 5.9$ & & $11.1 \pm 8.7$ & & $20.4 \pm 12.7$ & \\
\hline No & $94(92.2)$ & $4.2 \pm 5.0$ & & $4.0 \pm 4.5$ & & $5.4 \pm 7.9$ & \\
\hline Smoking & & & 0.007 & & $<0.001$ & & 0.032 \\
\hline Yes & $16(15.7)$ & $8.3 \pm 7.0$ & & $8.9 \pm 8.0$ & & $11.1 \pm 12.2$ & \\
\hline No & $86(84.3)$ & $4.3 \pm 5.1$ & & $3.8 \pm 4.2$ & & $5.7 \pm 8.4$ & \\
\hline CT finding & & & 0.979 & & 0.802 & & 0.056 \\
\hline Yes & $67(77.9)$ & $4.9 \pm 5.4$ & & $4.2 \pm 4.9$ & & $7.4 \pm 9.5$ & \\
\hline No & $19(22.1)$ & $4.9 \pm 5.5$ & & $4.3 \pm 3.9$ & & $3.9 \pm 7.1$ & \\
\hline Intensive care history due & & & 0.655 & & 0.292 & & 0.193 \\
\hline Yes & $5(4.9)$ & $6.0 \pm 6.8$ & & $7.0 \pm 4.9$ & & $11.8 \pm 14.0$ & \\
\hline No & $97(95.1)$ & $4.8 \pm 5.6$ & & $4.5 \pm 5.2$ & & $6.3 \pm 8.9$ & \\
\hline Do you have any complai & charge? & & 0.115 & & 0.013 & & 0.051 \\
\hline Yes & 73 (71.6) & $5.5 \pm 6.1$ & & $5.4 \pm 5.6$ & & $7.7 \pm 10.4$ & \\
\hline No & $29(28.4)$ & $3.5 \pm 3.8$ & & $2.6 \pm 3.3$ & & $3.7 \pm 4.5$ & \\
\hline Does the lack of long-last & ty cause you & axiety? & 0.003 & & 0.003 & & 0.009 \\
\hline Yes & $70(68.6)$ & $6.0 \pm 5.9$ & & $5.6 \pm 5.7$ & & $8.2 \pm 10.1$ & \\
\hline No & $32(31.4)$ & $2.5 \pm 3.8$ & & $2.3 \pm 3.2$ & & $3.0 \pm 5.5$ & \\
\hline Has any relative been infe & OVID-19? & & 0.991 & & 0.278 & & 0.750 \\
\hline Yes & $58(56.9)$ & $4.9 \pm 5.7$ & & $4.1 \pm 4.7$ & & $6.3 \pm 8.9$ & \\
\hline No & $44(43.1)$ & $4.9 \pm 5.5$ & & $5.2 \pm 5.9$ & & $6.9 \pm 9.7$ & \\
\hline Did any family member $\mathrm{d}$ & OVID-19? & & 0.387 & & 0.419 & & 0.982 \\
\hline Yes & $99(97.1)$ & $7.7 \pm 6.0$ & & $7.0 \pm 3.0$ & & $6.7 \pm 7.6$ & \\
\hline No & $3(2.9)$ & $4.8 \pm 5.6$ & & $4.5 \pm 5.3$ & & $6.5 \pm 9.3$ & \\
\hline
\end{tabular}

Mann Whitney U test was used in variables with two categories, and Kruskal Wallis test was used in more than two categories. Significance of $\mathrm{p}<0.05$ was accepted.

Table 2. Comparison of the scale scores according to the hospitalization dates of the survivors

\begin{tabular}{|c|c|c|c|c|c|c|c|}
\hline & \multirow[b]{2}{*}{ N (\%) } & \multicolumn{2}{|c|}{ GAD-7 } & \multicolumn{2}{|c|}{ PHQ-9 } & \multicolumn{2}{|c|}{ PTSD score } \\
\hline & & mean $( \pm \mathrm{SD})$ & $\mathrm{p}$ & mean $( \pm \mathrm{SD})$ & $\mathrm{p}$ & mean $( \pm \mathrm{SD})$ & $\mathrm{p}$ \\
\hline April & $6(5.9)$ & $4.8 \pm 5.7$ & & $8.0 \pm 8.7$ & & $10.7 \pm 13.0$ & \\
\hline May & $5(4.9)$ & $9.4 \pm 6.4$ & & $4.4 \pm 4.0$ & & $3.6 \pm 4.8$ & \\
\hline June & $13(12.7)$ & $2.6 \pm 4.4$ & 0036 & $2.6 \pm 3.8$ & 0,40 & $1.8 \pm 4.9$ & 0013 \\
\hline July & $20(19.6)$ & $3.1 \pm 4.3$ & 0.050 & $3.0 \pm 3.6$ & 0.049 & $3.7 \pm 6.4$ & 0.015 \\
\hline August & $56(54.9)$ & $5.4 \pm 5.7$ & & $4.7 \pm 4.9$ & & $7.9 \pm 9.7$ & \\
\hline September & $2(2.0)$ & $13.0 \pm 7.1$ & & $18.0 \pm 8.5$ & & $23.5 \pm 10.6$ & \\
\hline
\end{tabular}


Whereas $36.3 \%$ of the patients never felt that the people around them were afraid of them, $4.9 \%$ felt this a little bit, $34.3 \%$ moderately, $6.9 \%$ severely and $19.6 \%$ felt very seriously. Meanwhile $64.7 \%$ of the patients were never subjected to insulting and ridiculing, 15.7\% of them were subjected very seriously. Data on the perceptions of discrimination experienced by the participants due to COVID-19 are shown in Table 3.

\section{Risk factors leading to moderate and higher psychological response}

When GAD-7 scale scores analysis was done by categorizing as moderate and above; the rate of women having moderate and above anxiety (31.1\%) was significantly higher than the rate of men having moderate and above anxiety $(12.3 \%)(p=0.02)$. The rate of those with psychiatric disorder having moderate and above anxiety $(87.5 \%)$ was considerably higher than the rate of those without psychiatric disorder (14.9\%) $(\mathrm{p}<0.001)$.

Similarly, when the PHQ-9 scores was categorized and analyzed, the rate of those with psychiatric illnesses moderate and above depression (50.0\%) was found to be significantly higher than the rate of $(10.6 \%)$ those without psychiatric illness $(\mathrm{p}=0.012)$.

The moderate and above rate of anxiety of smokers $(43.8 \%)$ was determined significantly higher than the rate of non-smokers $(16.3 \%)(\mathrm{p}=0.02)$. The moderate and above rate of depression $(43.8 \%)$ of smokers was observed as significantly higher than the rate of nonsmokers $(8.1 \%)(p=0.001)$. The rate of those who experienced anxiety due to the lack of long-lasting immunity having moderate and above anxiety (90.5\%) was found significantly higher than the rate of those who did not cause anxiety $(9.5 \%)(\mathrm{p}=0.015)$.

When the PTSD scale scores were categorized as significant and insignificant, the rate of women having significant PTSD (33.2\%) was found to be significantly higher than that of men $(12.3 \%)(p=0.01)$. Significant PTSDs of those with psychiatric disorder $(75 \%)$ was found to be significantly higher than the rate of those without psychiatric disorder (17\%) $(p=0.001)$. Data on the analysis of risk factors that cause moderate and higher psychological response are shown in Table 4.

\section{The relationship between measurable variables and levels of psychological response}

There was a significant positive correlation among age, BMI and duration of hospitalization; and a significant negative relationship between age and PHQ-9. There was a significant positive correlation among GAD-7, PHQ-9 and PTSD. Likewise, a significant positive correlation was found between PHQ-9 and PTSD. There was a significant positive correlation between perceived discrimination scores and all scale scores. The relationship between measurable variables and psychological response levels is shown in Table 5.

Table 3. Perceived discrimination levels experienced by the participants due to COVID-19

\begin{tabular}{lccccc}
\hline & never & a little & moderate & severe & very serious \\
\hline Have you been excluded by family members because of your illness? & $86(84.3)$ & $5(4.9)$ & $5(4.9)$ & $4(3.9)$ & $2(2.0)$ \\
Have you been excluded by the community or people at work? & $42(41.2)$ & $5(4.9)$ & $32(31.4)$ & $7(6.9)$ & $16(15.7)$ \\
Have you ever felt that the people around you are afraid of you? & $37(36.3)$ & $5(4.9)$ & $35(34.3)$ & $5(4.9)$ & $20(19.6)$ \\
Have you been subjected to insulting or ridiculing? & $66(64.7)$ & $4(3.9)$ & $16(15.7)$ & - & $16(15.7)$ \\
\hline
\end{tabular}

*Line percentage is used

Table 4. Analysis of the factors that lead to moderate and above psychological responses

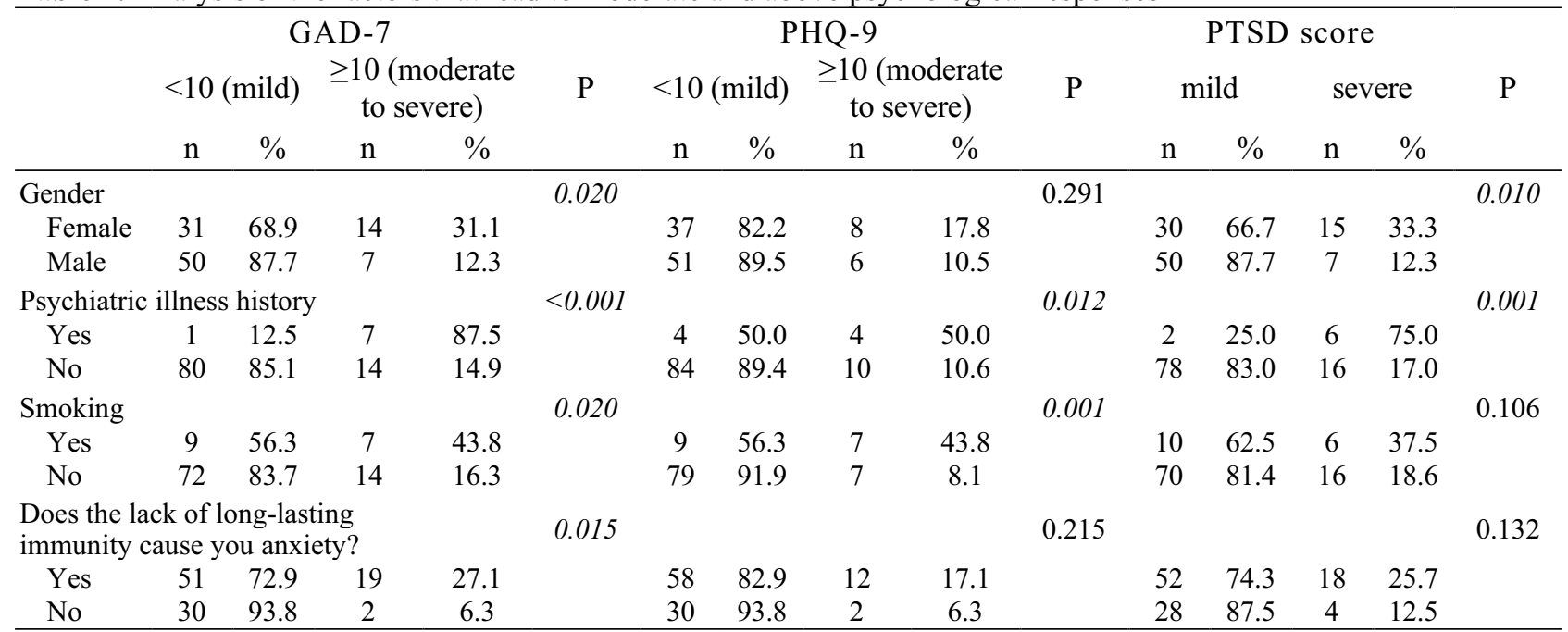

Spearman correlation analysis was performed. ${ }^{*} \mathrm{p}<0.05 * * \mathrm{p}<0.01$ 
Table 5. Correlation between age, BMI, duration of hospitalization and scale scores

\begin{tabular}{|c|c|c|c|c|c|c|c|}
\hline & & Age & BMI & Dur-of-hosp & GAD-7 & PHQ-9 & PTSD score \\
\hline \multirow[t]{2}{*}{ BMI } & $\mathrm{r}$ & $0.389^{* *}$ & & & & & \\
\hline & $\mathrm{p}$ & 0.000 & & & & & \\
\hline \multirow[t]{2}{*}{ Dur-of-hosp } & $\mathrm{r}$ & $0.372^{* *}$ & 0.026 & & & & \\
\hline & $\mathrm{p}$ & 0.000 & 0.794 & & & & \\
\hline \multirow[t]{2}{*}{ GAD-7 } & $\mathrm{r}$ & -0.099 & 0.057 & -0.030 & & & \\
\hline & $\mathrm{p}$ & 0.320 & 0.567 & 0.764 & & & \\
\hline \multirow[t]{2}{*}{ PHQ-9 } & $\mathrm{r}$ & $-0.198^{*}$ & -0.054 & -0.055 & $0.725^{* *}$ & & \\
\hline & $\mathrm{p}$ & 0.046 & 0.589 & 0.584 & 0.000 & & \\
\hline \multirow[t]{2}{*}{ PTSD score } & $\mathrm{r}$ & 0.064 & 0.072 & 0.057 & $0.736^{* *}$ & $0.790^{* *}$ & \\
\hline & $\mathrm{p}$ & 0.521 & 0.473 & 0.571 & 0.000 & 0.000 & \\
\hline \multirow[t]{2}{*}{ Discrimination } & $\mathrm{r}$ & 0.143 & 0.132 & 0.144 & $0.290^{* *}$ & $0.223^{*}$ & $0.253^{*}$ \\
\hline & $\mathrm{p}$ & 0.152 & 0.187 & 0.150 & 0.003 & 0.025 & 0.010 \\
\hline
\end{tabular}

Dur-of-hosp: Duration of hospitalization; Spearman correlation analysis was performed, ${ }^{*} \mathrm{p}<0.05 ; * * \mathrm{p}<0.01$

Table 6. Factors Related to Psychological Response Determined by Multivariate Logistic Regression Analysis

\begin{tabular}{lccc}
\hline Variables & b coefficient (SE) & Odds ratio $(95 \% \mathrm{CI})$ & $\mathrm{p}$ \\
\hline Anxiety & & & \\
$\quad$ Gender (female) & $1.171(0.516)$ & $3.2(1.2-3.2)$ & 0.023 \\
Psychiatric illness history & $3.689(1.108)$ & $40(4.5-350.6)$ & 0.001 \\
$\quad$ Smoking & $1.386(0.582)$ & $4(1.2-12.5)$ & 0.017 \\
$\quad$ Lack of long-lasting immunity & $1.721(0.778)$ & $5.6(1.2-25.7)$ & 0.027 \\
$\quad$ Discrimination & $0.141(0.055)$ & $1.2(1.1-1.3)$ & 0.01 \\
Depression & & & \\
$\quad$ Psychiatric illness history & $1.128(0.782)$ & $8.4(1.8-38.9)$ & 0.007 \\
$\quad$ Smoking & $2.172(0.640)$ & $8.8(2.5-30.8)$ & 0.001 \\
Discrimination & $1.120(0.686)$ & $1.2(1.1-1.3)$ & 0.049 \\
PTSD & & & \\
$\quad$ Gender (female) & $1.273(0.513)$ & $3.6(1.3-9.7)$ & 0.013 \\
Psychiatric illness history & $2.683(0.861)$ & $14.6(2.7-79)$ & 0.002 \\
Discrimination & $0.131(0.053)$ & $1.1(1.05-1.2)$ & 0.02 \\
\hline
\end{tabular}

Logistic regression analysis was applied. Significance of $\mathrm{p}<0.05$ was accepted

\section{Risk factors determined by logistic regression analysis}

According to the logistic regression analysis, being a woman (OR, 3.2, 95\% CI [1.2-3.2]), having a psychiatric illness (OR, 40, 95\% CI [4.5-350.6]), smoking (OR, $4,95 \%$ CI [1.2-12.5]), anxiety caused by lack of longlasting immunity (OR, 5.6, 95\% CI [1.2-25.7]), and experiencing discrimination (OR, 1.2, 95\% CI [1.1-1.3]) posed a risk for moderate and above anxiety.

Having a psychiatric illness (OR, 8.4, 95\% CI [1.838.9]), smoking (OR, 8.8 95\% CI [2.5-30.8]) and experiencing discrimination (OR, 1. 2, 95\% CI (1.1-1.3]) posed a risk for moderate and above depression.

Likewise, being a woman (OR, 3.6, 95\% CI [1.39.7]), having a psychiatric illness (OR, 14.6, 95\% CI [2.7-79]), and experiencing discrimination (OR, 1.1, 95\% CI [1.05-1.2]) were found to be the risk factors for PTSD. Risk factors determined by multivariate logistic regression analysis are shown in Table 6.

\section{DISCUSSION}

In this study, significant results were obtained for determining psychological response and related factors in discharged patients who were infected with COVID19 within the first 6-month period of the pandemic.

In our study, based on the moderate and above psychological response rates, anxiety was found in $20.6 \%$ and depression in $13.7 \%$ of the patients although a period of at least 2 months after discharge passed. Even though this result is consistent with studies related to the pandemic, it was a high result in terms of the prevalence of mental illness among the general Turkish population as the prevalence for any anxiety disorder is $7.4 \%$, and $7.3 \%$ for any mood disorder (Kılıç 1998). In addition, significant PTSD was detected in $21.6 \%$ of the participants. Bo et al. found the rate of PTSD to be $96.2 \%$ (Bo et al. 2020), and Liu et al. found 12.4\% (Liu et al. 2020). Bo et al. conducted their studies in the pre-discharge period (severe symptoms, intensive treatment and isolation period), which was an expected result of high trauma rates during this period. On the other hand, Liu et al. conducted their studies in the first month after discharge, but in this study, only $32 \%$ of the patients had ongoing symptoms. This was considerably lower than the rates we achieved $(71.6 \%)$. This difference may be due to the severity of the disease and the presence of ongoing symptoms as well as the time of 
the research. We also found that PTSD rates could change over time, but did not disappear completely over the 6-month period. Considering that PTSD symptoms persist for many years and may impair the quality of life, this result indicates the need to pay attention to psychiatric follow-up of patients for a long time (Ahmed et al. 2020, Park et al. 2020b).

Another aim of our study was to identify the factors that lead to psychological response. In this study, as in the pre-pandemic studies (Lim et al. 2018, Olff 2017) it was observed that the psychological response levels of women were higher than men. Also, the presence of comorbid physical and psychiatric disorder were found to be factors associated with increased psychological response (COVID-19 Response Team 2020, Mei et al. 2021). In addition, the presence of ongoing symptoms was associated with depression.

Surprisingly, while increasing age led to prolonged hospital stays, it was a preventative factor, especially in terms of developing depression. The present finding was consistent with studies suggesting that older adults tend to have less negative emotions, better mental health, and less responsiveness to daily stress factors, and therefore experience less depression (Bruine 2021). Despite being shown as the target population for the COVID-19 pandemic (Surveillances 2020), this situation in older adults has led to the idea that these people can regulate their emotions by focusing on the positive and choosing activities and interactions that reduce stress (Carstensen et al. 2000, Neubauer et al. 2020, Neupert \& Bellingtier 2019). On the other hand, this result made us think about the possibility that elderly people may display inappropriate behaviors by ignoring the risk. Therefore, we believe that the follow-up of these people should not be neglected.

Although smoking is a particularly risky behavior for COVID-19 (Lohia et al. 2021) and quitting has been shown to be associated with many positive health effects, including improvement in lung function and respiratory symptoms (Rojnić et al. 2020), interestingly $16 \%$ of our participants continued to smoke. In addition, smoking was found to be associated with increased psychological response. Previous studies have also found a relationship between smoking and psychiatric disorders, but the mechanisms underlying this relationship have not been fully elucidated (Firth et al. 2020, Ho et al. 2019). The general view is that smoking is not a causal factor for anxiety and depression, the "selfmedication" hypothesis seems more reasonable (Bjørngaard et al. 2013). Perhaps these people used smoking to relax while dealing with the pandemic or they did not want to quit smoking, thinking that their distress would be intensified. Although our study does not have a design to explain this causality, it may serve as a guide for future researches.

The lack of long-lasting immunity against COVID19 has been found to be associated with high anxiety scores in patients. It seems reasonable that the possibility of re-catching a disease for which there is no effective treatment yet and what complications it will cause in the future is a cause for concern.

Another result of our study was that the majority of the participants stated that they were more or less excluded by their environment, which was also a factor that determined both the occurrence and severity of all three psychiatric disorders. Indeed, considering that the stigma and discrimination are associated with psychological trauma that continues for many years (Park et al. 2020b, Liu et al. 2020), this result could determine the direction of the measures to be taken to protect the mental health of the patients. Because the exclusion of people by their environment even after their discharge will cause these people to regress in their social and professional areas and the feeling of shame, guilt, or worthlessness may lead to the deterioration of their mental health (Dar et al. 2020). On the other hand, stigma may cause patients to hide their disease, restrict their search for healthcare services, and display unhealthy behaviors (UNICEF 2020). This can pose a significant risk not only for personal health but also for public health.

Additionally, unlike the literature (Theano et al. 2020), in our study, no relationship was found between the duration of hospitalization, the presence of lung involvement, and intensive care treatment and psychological response. Although our working in a relatively small number of patient groups seems to have caused this difference, this result once again showed that the effect of COVID-19 on mental health surpasses physical illness (Torales et al. 2020).

This study has some limitations such as the low rate of intensive care patients, the fact that clinical severity is not classified, and the psychiatric evaluation is based on self-reporting. In addition, the results may not reflect the general population, as the study only covered patients in a particular region.

\section{CONCLUSION}

The psychological effects of COVID-19 continue after discharge and may cause significant mental illness in survivors. More than half of the patients, who were relatively severe enough to require hospitalization, had moderate and higher levels of anxiety, depression and PTSD after an average of 2 months after discharge. A history of psychiatric disorder and high discrimination perception were associated with all three mental illnesses. In addition, female gender, presence of comorbid diseases, smoking, and lack of long-lasting immunity of the disease were risk factors in terms of psychological response. Ensuring that these COVID-19 survivors receive psychological support and informing the public about stigmatization will benefit the longterm mental health of the society. 


\section{Acknowledgements: None.}

\section{Conflict of interest: None to declare.}

\section{Contribution of individual authors:}

Neslihan Cansel: concept and design of the article; literature searches; writing and manuscript; approval of the final version.

Burcu Kayhan Tetik \& Gülsüm Hilal Demir: collected the data, manuscript preparation.

Osman Kurt: performed the statistical analysis,

Bahri Evren \& Aytac Yücel: literature research, manuscript preparation.

\section{References}

1. Ahmed H, Patel K, Greenwood DC, Halpin S, Lewthwaite $P$, Salawu A et al.: Long-term clinical outcomes in survivors of severe acute respiratory syndrome (SARS) and Middle East respiratory syndrome (MERS) coronavirus outbreaks after hospitalisation or ICU admission: a systematic review and meta-analysis. J Rehabil Med 2020; 52:1-11

2. Bjørngaard JH, Gunnell D, Elvestad MB, Davey Smith G, Skorpen F, Krokan H et al.: The causal role of smoking in anxiety and depression: a Mendelian randomization analysis of the HUNT study. Psychol Med 2013; 43(4): 711-719

3. Bo HX, Li W, Yang Y, Wang Y, Zhang $Q$, Cheung $T$ et al.: Posttraumatic stress symptoms and attitude toward crisis mental health services among clinically stable patients with COVID-19 in China. Psychol Med 2020;27:1-2.

4. Bruine de Bruin W: Age Differences in COVID-19 Risk Perceptions and Mental Health: Evidence From a National U.S. Survey Conducted in March 2020. J Gerontol B Psychol Sci Soc Sci 2021; 7:e24-e29

5. Carstensen LL, Pasupathi M, Mayr U, Nesselroade JR: Emotional experience in everyday life across the adult life span. J Pers Soc Psychol 2000; 79(4): 644-55

6. CDC COVID-19 Response Team: Preliminary Estimates of the Prevalence of Selected Underlying Health Conditions Among Patients with Coronavirus Disease 2019 - United States, February 12-March 28, 2020. MMWR. Morbidity and mortality weekly report 2020; 69:382-386

7. Dar SA, Khurshid SQ, Wani ZA, Khanam A, Haq I, Shah NN et al.: Stigma in coronavirus disease-19 survivors in Kashmir, India: A cross-sectional exploratory study. PloS one 2020; 15(11): e0240152

8. Evren C, Dalbudak E, Aydemir O, Koroglu E, Evren B, Ozen $S$ et al.: Psychometric properties of the Turkish PTSD-Short Scale in a sample of undergraduate students. Klinik Psikofarmakoloji Bülteni-Bulletin of Clinical Psychopharmacology 2016; 26(3): 294-302

9. Firth J, Solmi M, Wootton RE, Vancampfort D, Schuch $F B$, Hoare $E$ et al.: A meta-review of "lifestyle psychiatry": the role of exercise, smoking, diet and sleep in the prevention and treatment of mental disorders. World Psychiatry 2020; 19:360-380

10. Gorbalenya AE, Baker SC, Baric RS, de Groot RJ, Drosten C, Gulyaeva AA et al.: Coronaviridae Study
Group of the International Committee on Taxonomy of Viruses. The species severe acute respiratory syndromerelated coronavirus: classifying 2019-nCoV and naming it SARS-CoV-2. Nat Microbiol 2020; 5:536-544

11. Ho C, Tan E, HoR, Chiu M: Relationship of Anxiety and Depression with Respiratory Symptoms: Comparison between Depressed and Non-Depressed Smokers in Singapore. Int J Environ Res Public Health 2019; 16:163

12. Holmes EA, O'Connor RC, Perry VH, Tracey I, Wessely S, Arseneault $L$ et al.: Multidisciplinary research priorities for the COVID-19 pandemic: a call for action for mental health science. The Lancet Psychiatry 2020; 7:547-560

13. Huang X, Wei F, Hu L, Wen L, Liao G, Su J \& Chen K: The Post-Traumatic Stress Disorder Impact of the COVID-19 Pandemic. Psychiatr Danub 2020; 32(34): $587-589$

14. James PB, Wardle J, Steel A, Adams J: Post-Ebola psychosocial experiences and coping mechanisms among Ebola survivors: a systematic review. Trop Med Int Health 2019; 24, 671-691

15. Kılıç C: Erişkinlerle ilgili sonuçlar. Türkiye Ruh Sağlı̆̆ Profili: ana rapor; Erol N, Kllıç C, Ulusoy M, Keçeci M, Şimşek Z (eds): Sağlık Bakanlığı Yayınları 1998, Ankara.

16. Konkan R., Şenormancı Ö, Güçlü O, Aydin E, Sungur MZ: Yaygın Anksiyete Bozukluğu-7 (YAB-7) Testi Türkçe Uyarlamast, Geçerlik ve Güvenirliği.Archives of Neuropsychiatry/Noropsikiatri Arsivi 2013; 50(1)

17. Kroenke K, Spitzer RL, Williams JB: The PHQ-9: validity of a brief depression severity measure. J Gen Intern Med 2001;16(9):606-13

18. LeBeau R, Mischel E, Resnick H, Kilpatrick D, Friedman M, Craske M: Dimensional assessment of posttraumatic stress disorder in DSM-5. Psychiatry Res 2014; 15;218(12): $143-7$

19. Lim GY, Tam WW, Lu Y, Ho CS, Zhang MW, Ho RC: Prevalence of Depression in the Community from 30 Countries between 1994 and 2014. Sci Rep 2018; 8(1): 2861

20. Liu D, Baumeister RF, Veilleux JC, Chen C, Liu W, Yue Y \& Zhang S: Risk factors associated with mental illness in hospital discharged patients infected with COVID-19 in Wuhan, China. Psychiatry Res 2020 Oct;292:113297

21. Lohia P, Sreeram K, Nguyen P, Choudhary A, Khicher S, Yarandi $H$ et al.: Preexisting respiratory diseases and clinical outcomes in COVID-19: a multihospital cohort study on predominantly African American population. Respir Res 2021; 22(1): 37

22. Mak IW, Chu CM, Pan PC, Yiu MG, Chan V: Long-term psychiatric morbidities among SARS survivors. Gen Hosp Psychiatry 2009; Jul-Aug;31(4):318-326.

23. Mei Q, Wang F, Bryant A, Wei L, Yuan X, Li J: Mental health problems among COVID-19 survivors in Wuhan. China. World Psychiatry 2021; 20(1): 139-140

24. Neubauer AB, Smyth JM, Sliwinski MJ: Age Differences in Proactive Coping With Minor Hassles in Daily Life. J Gerontol B Psychol Sci Soc Sci 2019 Jan 1;74(1):7-16

25. Neupert SD \& Bellingtier JA: Daily Stressor Forecasts and Anticipatory Coping: Age Differences in Dynamic, Domain-Specific Processes. J Gerontol B Psychol Sci Soc Sci 2019 1;74(1):17-28

26. Olff M: Sex and gender differences in post-traumatic stress disorder: an update. Eur J Psychotraumatol 2017; 8(4):1351204 
27. Park HY, Park WB, Lee SH, Kim JL, Lee JJ, Lee H \& Shin HS: Posttraumatic stress disorder and depression of survivors 12 months after the outbreak of Middle East respiratory syndrome in South Korea. BMC Public Health 2020(a); 15;20(1):605

28. Park HY, Jung J, Park HY, Lee SH, Kim E S, Kim HB \& Song KH: Psychological Consequences of Survivors of COVID-19 Pneumonia 1 Month after Discharge. J Korean Med Sci 2020 (b) 7;35(47): 409

29. Rojnić Palavra I, Bodor D, Ostojić J, Štimac Grbić D, Rojnić Kuzman M: SARS-CoV-2 Coronavirus Pandemic: Now Is the Right Time to Stop Smoking. Psychiatr Danub 2020;32(2):308-309

30. Sari YE, Kokoglu B, Balcioglu H, Bilge U, Colak E, Unluoglu I: Turkish reliability of the patient health questionnaire-9. 2016

31. Sinanović O, Muftić M, Sinanović S: COVID-19 Pandemia: Neuropsychiatric Comorbidity and Consequences. Psychiatr Danub 2020; 32(2):236-244

32. Spitzer RL, Kroenke K, Williams JB, Löwe B: A brief measure for assessing generalized anxiety disorder: the GAD-7. Arch Intern Med 2006; 22;166(10):1092-7

33. Surveillances $V$ : The epidemiological characteristics of an outbreak of 2019 novel coronavirus diseases (COVID-19) - China, 2020. China CDC weekly 2020; 2(8): 113-122

34. Theano P, Periklis $P$, Vasilis $P$, Elli $K$, Dimitrios $P$ : SARSCoV-2 Psychosomatic Effects and Fear of Stigma on the Discharge Day of Infected Individuals: SAPFO Study. Psychiatr Danub 2020;32(3-4):577-580

35. Torales J, O'Higgins M, Castaldelli-Maia JM, Ventriglio A: The outbreak of COVID-19 coronavirus and its impact on global mental health. Int J Soc Psychiatry 2020; 66:317-320

36. UNICEF: Social stigma associated with COVID-19: a guide to preventing and addressing social stigma. 2020. Available from: https://www.unicef.org/documents/socialstigma-associated-coronavirus-disease-covid-19. (accessed Feb 28, 2021)

37. WHO Director-General's opening remarks at the media briefing on COVID-19 - 11 March 2020 (2020a). Available from: https://www.who.int/dg/speeches/detail/whodirector-general-s-opening-remarks-at-the-media-briefingon-covid-19\%2D\%2D-11-march-2020. (accessed Feb 28, 2021)

38. Wing YK \& Leung CM: Mental health impact of severe acute respiratory syndrome: a prospective study. Hong Kong Med J 2012; 18(3):24-27

39. WHO (2020b): Coronavirus Disease (COVID-19) Dashboard. Available from: https://covid19. who. int. (accessed Feb 23, 2021)

40. Xiang YT, Yang Y, Li W, Zhang L, Zhang Q, Cheung T \& $\mathrm{Ng}$ CH: Timely mental health care for the 2019 novel coronavirus outbreak is urgently needed. Lancet Psychiatry 2020;7(3):228-229

41. Xiao S, Luo D, Xiao Y: Survivors of COVID-19 are at high risk of posttraumatic stress disorder. Glob Health Res Policy 2020;5:29

42. Zhu S, Gao Q, Yang L, Yang Y, Xia W, Cai X et al.: Prevalence and risk factors of disability and anxiety in a retrospective cohort of 432 survivors of Coronavirus Disease-2019 (Covid-19) from China. PLoS One 2020;15(12):e0243883

Correspondence:

Assist. Professor Neslihan Cansel, MD

Department of Psychiatry, Inonu University Medical Faculty

Malatya, Turkey

Email:neslihancansel@yahoo.com.tr 